\title{
Matriz legal en el sistema gestión de seguridad y salud de trabajo*
}

\author{
Legal matrix in the workplace health and safety management system
}

Ángela Patricia Marrugo Padilla'

Fecha correspondencia:

Recibido: 23 de noviembre de 2020.

Revisión: 10 de abril de 2021.

Aceptado: 19 de abril de 2021.

Forma de citar:

Marrugo, Ángela Patricia. (2021)

"Matriz legal en el sistema gestión

de seguridad y salud de trabajo." En:

Revista CES Derecho. Vol. 12, №. 1,

enero a junio de 2021, p. 79-107.

Open access

Términos de uso

Licencia creative commons

Etica de publicaciones

Revisión por pares

Gestión por Open Journal System

DOI: http://dx.doi.org/10.21615/

cesder.12.1.5

ISSN: 2145-7719

Sobre el artículo:

* Artículo de reflexión derivado

del proyecto de investigación

Propuesta metodológica para la

elaboración y entendimiento de

la matriz legal en el sistema de

seguridad y salud en el trabajo en

Colombia.

\section{Sobre los autores:}

1. Abogada. Especialista en

Gerencia de la Seguridad y Salud en

el Trabajo Universidad del Rosario

en convenio con Universidad CES.

Facultad de Medicina. Universidad CES.

\section{Resumen}

La puesta en marcha del Sistema de Gestión en Seguridad y Salud en el Trabajo (SG SST) comprende un desafío para cada uno de los actores que intervienen en el Sistema de Riesgos Laborales en Colombia. En cuanto a la exigencia de la matriz legal, como la documentación que contiene los requisitos normativos para las empresas en materia de seguridad y salud en el trabajo, supone un arduo ejercicio de conocimiento, compilación y articulación de las normas vigentes en riesgos laborales. Lo anterior se simplificaría si se plantea una metodología que lleve a proponer los componentes básicos y su articulación de forma comprensible y sencilla que en ultimas representaría grandes ventajas para la empresa tanto en la prevención de accidentes y enfermedades laborales como en términos económicos. Para lo anterior, se elaboró una descripción detallada de una propuesta para la creación de la matriz legal, basándose en una metodología cualitativa de revisión documental.

Palabras claves: Seguridad y salud en el trabajo, jerarquía normativa, Sistema General de Riesgos Laborales, Sistema de Gestión en Seguridad y Salud en el Trabajo SG-SST, matriz legal.

\section{Abstract}

The implementation of the new model of the Occupational Health and Safety Management System (SG SST) involves a challenge for each of the actors involved in the Occupational Risk System in Colombia. As for the requirements of the legal matrix, such as the documentation that contains the regulatory requirements for companies in matters of occupational health and safety, it involves an arduous exercise of knowledge, compilation and articulation of the current regulations on occupational risks. The foregoing would be simplified if a methodology is established that leads to proposing the basic components and their articulation in an understandable and simple way that the latter would represent great advantages for the company both in the prevention of accidents and occupational diseases and in financial terms. For that, it was developed a full detail description of a legal matrix, under the qualitative methodology of documents search.

Keywords: Occupational safety and health, hierarchy of norms, Occupational Risk System, Occupational safety and health management system, Legal matrix. 


\section{Introducción}

En desarrollo de la consagración del derecho a la seguridad social, como un derecho social irrenunciable en cabeza del Estado, en el artículo 48 de la Constitución Política de1991 y con la entrada en vigencia de la Ley 100 de 1993 (Congreso de la República; 1993) se creó el Sistema General de Seguridad Social Integral, conformado a su vez por cuatro sistemas generales: pensiones, salud, riesgos profesionales y servicios sociales complementarios. Desde entonces reglamentar el Sistema de Riesgos Profesionales, hoy llamado Sistema de Riesgos Laborales, supuso un gran desafío por la producción legislativa desordenada y generada a gran escala, pues resulta el enfrentamiento a un sin números de normas dispersas y confusas. A su vez, al responsable de la seguridad y salud en el trabajo se le impone la obligatoriedad de que la normatividad se mantengan disponible y actualizada y con la debida evidencia de cumplimiento.

La matriz legal siendo el compendio de normas vigentes en materia de seguridad y salud en el trabajo resulta ser un gran desafío para los responsables de implementar el Sistema de Gestión en Seguridad y Salud en el Trabajo. Este articulo expondrá brevemente el andamiaje teórico que sirve de soporte en la elaboración y entendimiento de dicha matriz legal. En primer lugar, se abordará el origen y concepto del principio de jerarquía de normas con el fin de explicar de forma general el sistema jurídico colombiano. En segundo lugar, se expondrán una a una las definiciones que conforma la jerarquía normativa en materia de seguridad y salud en trabajo en Colombia. Por último, se abarcará el tema central de este artículo: la matriz legal, explicando sus antecedentes, definición y ventajas, para finalmente establecer los componentes que llevan a plantear una metodología fácil y sencilla de entender y crear dicha matriz legal. La metodología utilizada para la realización de este trabajo fue de búsqueda y análisis documental bajo un modelo cualitativo de síntesis de la información, de modo que se pudiese presentar una propuesta útil para los encargados de elaborar la matriz legal.

\section{El principio de jerarquía normativa en el ordenamiento jurídico colombiano}

Para abordar el estudio de las principales definiciones normativas del ordenamiento jurídico colombiano resulta pertinente entender en primer lugar el principio de jerarquía normativa.

La jerarquía normativa es un concepto propuesto por el filósofo y jurista vienés Hans Kelsen en su libro la Teoría Pura del Derecho.. Según Hans Kelsen (trad. En 2009) un conjunto de normas constituye un orden cuando su validez reposa en una única norma, esa única norma la llamó norma fundamental; como la fuente de validez del orden jurídico y es así, que dicha norma fundamental determinará el cómo deben ser creadas y cuál es el contenido de las demás normas. Asimismo, explicó que la relación existente entre dichas normas es que una norma resulta ser el fundamento de la otra, por lo que se acude a la noción de norma superior y norma inferior respectivamente.

En consecuencia, la jerarquía normativa no se trata pues de una mera definición si no de un principio que permea todo el ordenamiento jurídico, es decir; armoniza su coherencia interna y a su vez establece las normas de rango superior que resultan ser la fuente de validez de las demás normas que le siguen en dicho orden, cerciorándose así de conservar coherencia y desarrollarlas de forma particular. En otras palabras "no es otra que la de establecer un orden que permita regular conforme a un mismo 
sistema axiológico, las distintas situaciones de hecho llamadas a ser normadas por el ordenamiento jurídico. "(Corte Constitucional, Sentencia C-037, 200).

Si bien en el ordenamiento jurídico colombiano no existe una disposición expresa que consagre el principio de la jerarquía normativa o una que establezca un orden jerárquico preciso y completo de las leyes, la Constitución Política de Colombia en varios de sus artículos da lugar a ella en el sentido de establecer el rango de prevalencia de ciertas normas frente a otras, verbigracia: "La Constitución es norma de normas. En todo caso de incompatibilidad entre la Constitución y la ley u otra norma jurídica, se aplicarán las disposiciones constitucionales."(Const., 1991, art. 4).

\section{La jerarquía normativa en materia de Seguridad y Salud en el Trabajo en Colombia}

Una vez que se ha entendido que el ordenamiento jurídico colombiano se basa en una escala jerárquica de normas; en donde las normas de inferior categoría, deben estar acorde con las superiores, y por tanto desarrollarlas de forma particular, resulta importante entender una a una las definiciones que hacen parte de dicha jerarquía, pues en el ejercicio de compilar, cumplir y actualizar los requisitos normativos que debe cumplir una empresa en materia de Seguridad y Salud en el Trabajo se encuentran distintos términos, tales como ley, decreto, resolución y demás que pueden llegar a confundir respecto el origen y la obligatoriedad de los mismos.

A continuación, se plantea una pirámide que establecen el orden jerárquico de las normas en Seguridad y Salud en el Trabajo en Colombia:

Figura 1. Pirámide de la jerarquía normativa en el Sistema de Gestión de Seguridad y Salud en el Trabajo.

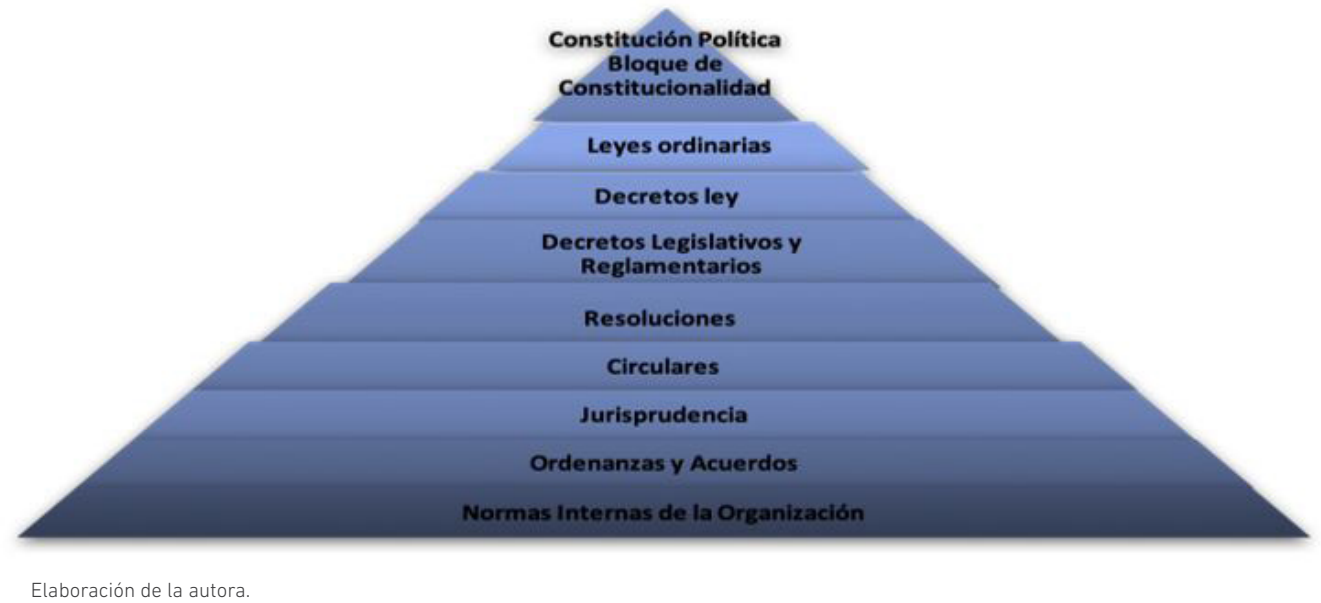

\section{La Constitución Política}

En virtud del artículo 4 de la Constitución Política, la misma es la norma superior dentro del ordenamiento jurídico colombiano, de allí su supremacía sobre las demás normas sean estas leyes, decretos, resoluciones u otra categoría jurídica, de modo que cualquiera otra que riña con lo establecido en ella supone su inconstitucionalidad y por ende su expulsión del ordenamiento jurídico. 
En la Constitución Política son varios los artículos que se relacionan con el asunto de Seguridad y Salud en el Trabajo: 1, 2, 11, 12, 13, 14, 15, 18, 19, 20, 21, 25, 29, 42, 43, $44,47,48,49,52,53$ y 54 . Sin embargo, el marco normativo del que surge el Sistema de Seguridad y Salud en el Trabajo son el articulo 48 sobre la seguridad social y el artículo 25 que establece el derecho al trabajo.

El derecho al trabajo goza de especial protección por parte del Estado, de esta manera, el derecho al trabajo supone la exigencia de su ejercicio en condiciones dignas y justas, es decir, "su realización en un entorno sin características humillantes o degradantes o que desconozca los principios mínimos fundamentales establecidos por la Constitución, y además que permita su desarrollo en condiciones equitativas para el trabajador."(Corte Constitucional, Sentencia C-107, 2002).

Tratados o Convenios Internacionales

Los tratados o convenios internacionales son acuerdos sobre determinadas materias suscritos entre países o estados parte de una organización internacional con el fin de seguir parámetros comunes.

Para entender el carácter vinculante de los tratados o convenios internacionales dentro del ordenamiento jurídico colombiano es fundamental abordar el concepto de bloque de constitucionalidad, un concepto nuevo que ha sido desarrollado por la Jurisprudencia de la Corte Constitucional y definido en los siguientes términos: "El bloque de constitucionalidad está compuesto por aquellas normas y principios que, sin aparecer formalmente en el articulado del texto constitucional, son utilizados como parámetros del control de constitucionalidad de las leyes, por cuanto han sido normativamente integrados a la Constitución, por diversas vías y por mandato de la propia Constitución." (Corte Constitucional, Sentencia C-067, 2003).

En resumen, el bloque de constitucionalidad puede explicar cómo la Constitución Política es un concepto amplio que va más allá de su propio texto e involucra otras disposiciones que también gozan el carácter de norma constitucional, verbigracia una norma de carácter supranacional, aquella norma que no se encuentra dentro del ordenamiento jurídico interno, se le otorgue de forma expresa un carácter constitucional, y por tanto se integra en el ordenamiento interno.

Asimismo, se ha establecido que el bloque de constitucionalidad goza de dos sentidos, el primero de ellos es el sentido restringido (stricto sensu) integrado por aquellas normas internacionales que cumplen con dos de los siguientes requisitos; el primero que tengan la remisión expresa del articulado constitucional y el segundo que versen sobre derechos humanos, derecho penal internacional, derecho internacional humanitario y normas sobre límites territoriales de Colombia. Por el contrario, el sentido amplio (lato sensu) está conformado por aquellas disposiciones normativas sin rango constitucional, pero que sirven como parámetro de interpretación para el control de constitucionalidad, entre estas encontramos leyes estatutarias, orgánicas y decisiones de jueces internacionales sobre derechos humanos. (Arango, 2004)

Ahora bien, en materia de trabajo se establece que los convenios internacionales de trabajo debidamente ratificados hacen parte de la legislación interna (Const., 1991, art. 53) es decir, adquieren el carácter de normas jurídicas obligatorias en el derecho nacional, por tanto, no requerirán de norma adicional que lo incorpore o desarrolle. Lo anterior, es un ejemplo claro del sentido estricto del bloque de constitucionalidad. 
La Organización Internacional de Trabajo OIT, resulta ser el marco referente de las normas internacionales de trabajo. La OIT es una agencia de la Organización de Naciones Unidas, conformada por los gobiernos, empleadores y trabajadores de sus estados miembros y que tiene como finalidad "establecer las normas del trabajo, formular políticas y elaborar programas promoviendo el trabajo decente de todos, mujeres y hombres" (OIT, s.f.)

Colombia es Estado miembro de la OIT desde su creación en el año 1919; a la fecha ha ratificado 61 convenios, de los cuales 54 se encuentran en vigor. Cuando un Estado ratifica un convenio esto significa que adquiere una obligación oficial de adecuar su normatividad nacional al mismo dentro de un término de 12 meses.

Ciertamente ser parte de la OIT significa para Colombia el compromiso de ir a la vanguardia de normas internacionales que promuevan la justicia social en materia de trabajo, adoptar instrumentos jurídicos que enfrenten los nuevos desafíos de una economía globalizada y procurar la seguridad y la salud de los trabajadores a través del concepto de trabajo decente.

En resumen, la OIT es el principal organismo internacional que orienta la legislación nacional en asuntos relacionados de seguridad y salud en el trabajo. A la fecha Colombia ha ratificado los siguientes convenios relacionados con esa temática: Convenio 174 sobre la Prevención de accidentes industriales mayores, Convenio161 sobre Servicios de Salud en el trabajo, Convenio 162 sobre la Utilización del asbesto en condiciones de seguridad, Convenio 013 sobre la cerusa (pintura), Convenio 136 sobre el benceno y Convenio 170 sobre los productos químicos.

Por otro lado, encontramos las recomendaciones, descritas como instrumentos jurídicos que, aunque no tenga el carácter de vinculante si complementan el convenio ratificado, (ILO, s.f) un ejemplo claro de una recomendación es la ILO OSH 2001 Directrices relativas a los sistemas de gestión de la seguridad y la salud en el trabajo.

Otro organismo internacional de gran importancia para Colombia es la Comunidad Andina de Naciones CAN, conformada por Bolivia, Colombia, Ecuador y Perú con el propósito de lograr un desarrollo integral, equilibrado y autónomo entre los países miembros. La Integración Andina se logró tras firmar el Acuerdo de Cartagena el 26 de mayo de 1969 con la voluntad de llevar a cabo acciones conjuntas en distintos ámbitos tales como acceso a mercado, sanidad agropecuaria, comercio, integración física, transformación productiva, servicios e inversiones, asuntos sociales, propiedad intelectual y otras áreas especiales. (CAN).

La seguridad social hace parte de los asuntos sociolaborales y es así que a través Decisión 584 del 07 de mayo de 2004, se adoptó el Instrumento Andino de Seguridad y Salud en el Trabajo, con el objetivo que los países miembros adopten medidas necesarias para mejor las condiciones de seguridad y salud en cada centro de trabajo de la subregión y así elevar el nivel de la integridad física y mental de los trabajadores (Decisión 584, 2004). En consecuencia, ésta se convierte en un instrumento jurídico de carácter internacional que fundamenta la adopción interna del Sistema de Gestión en SST en Colombia. 
2.2. Ley

El concepto de ley se encuentra definido en el artículo 4 del Código Civil Colombiano como la declaración de la voluntad soberana manifestada en la forma prevenida en la Constitución Nacional y establece que su carácter general es mandar, prohibir, permitir o castigar.

A su vez la Constitución Política Colombiana hace referencia a cuatro tipos de leyes: la leyes estatutarias definidas en el articulo 152 y 153 un ejemplo que aplica en esta materia es la Ley 1751 de 2015 por medio de la cual se regula el derecho fundamental a la salud; leyes orgánicas regladas de forma taxativa en el articulo 151; leyes marcos o cuadro que fijan un marco de acción al poder ejecutivo; y por último las leyes ordinarias, todas ellas promulgadas por el poder legislativo, es decir, el Congreso de la República de Colombia. En materia de seguridad y salud en el trabajo aplican las ordinarias.

\section{- Las Leyes Ordinarias}

Son aquellas leyes que no tiene la especificidad de ser leyes orgánicas, estatutarias o marco, y por tanto requerirán para su trámite de aprobación en el Congreso de la República de una mayoría simple. Dentro de esta clasificación se incluyen la mayor parte de las leyes que se relacionan con el tema de Seguridad y Salud en el Trabajo. Un claro ejemplo es la Ley 1562 de 2012, conocida como la Ley de Riesgos Laborales, la cual representó un gran avance del Sistema General de Riesgos Laborales, con ampliación de derechos a los trabajadores, la cobertura a un grupo de trabajadores que anteriormente no estaba incluidos y el planteamiento de la afiliación voluntaria, entre otras disposiciones que afianzaron la Seguridad y Salud en el trabajo en Colombia.

\subsection{Decretos}

Los Decretos son las disposiciones normativas que provienen de la rama ejecutiva sin la intervención del poder legislativo, por tanto en materia de seguridad y salud en el trabajo podrán ser promulgados por el Presidente de la República, gobernadores o alcaldes, Ministerio de Trabajo, Ministerio de Salud y Protección Social. A su vez los decretos presidenciales podrán ser:

\section{Decretos Extraordinarios o Decretos-Leyes}

Son los promulgados en ejercicio de una facultad extraordinaria otorgada por el Congreso para reglamentar asuntos de necesidad o conveniencia pública. El ejemplo por excelencia de este tipo de decreto es el Decreto 1295 de 1994 que estructuró la organización y administración del Sistema General de Riesgos Profesionales. Dicho Decreto nació a partir de la promulgación de la Ley 100 de 1993 que creó los cuatros sistemas de seguridad social integral, siendo el de riesgos profesionales uno de ellos, y en específico del artículo 139 que le otorgó facultades extraordinarias al Presidente de la República por el término de seis meses para dictar las normas necesarias para organizar el Sistema General de Riesgos Laborales. Es así que su articulado sentó las bases del hoy llamado Sistema General de Riesgos Laborales, definiendo su alcance, objetivos, conceptos, prestaciones, las entidades involucradas en su dirección, control y vigilancia, entre otros. 
Decretos Reglamentarios Ordinarios

Son los expedidos por el Presidente de la República en su calidad de suprema autoridad administrativa, o por sus ministros en ejercicio de la potestad reglamentaria conferida en el artículo 189 de la Carta Política, con el fin de reglamentar las leyes de forma detallada. El Decreto Único Reglamentario Sector Trabajo No. 1072 de 2015, sirve como ejemplo, el cual como instrumento jurídico único compiló y racionalizó las reglamentaciones preexistentes en el sector trabajo.

\section{Decretos Legislativos}

Son los expedidos en virtud de un estado de excepción. Existen tres tipos de estados de excepción: guerra exterior, la conmoción interior y la emergencia económica, social o ecológica. Un claro y reciente ejemplo es el Decreto 417 de de 17 de marzo de 2020 por el cual se declara un Estado de Emergencia Económica, Social y Ecológica en todo el territorio Nacional. A principios de 2020 la Organización Mundial de la Salud declaró como pandemia el brote del nuevo coronavirus como un asunto de emergencia de salud publica de orden internacional, en este orden de ideas el gobierno nacional declaró el estado emergencia económica, social y ecológica. Ahora bien, tal declaración de estado de emergencia permite la promulgación de Decretos Ley con el único fin de atender y reglamentar la crisis y sus efectos.

\subsection{Resoluciones \\ Las Resoluciones pueden ser definidas como:}

Providencias administrativas que tienen por objeto reglamentar puntos especiales del servicio público; o decidir cuestiones de fondo sobre contratos y en general poner término a las actuaciones administrativas cuando ellas hayan de tener un efecto determinado; o resolver sobre las solicitudes que formulen los ciudadanos de conformidad con la Constitución y las Leyes, o decidir definitivamente, por la vía gubernativa, sobre los asuntos que tenga interés o haya de resultar interesado un particular. (Sierra, 1999).

A su vez las resoluciones podrán ser dictadas por el ejecutivo, ministros, asambleas departamentales, gobernadores, alcaldes y demás funcionarios con dicha capacidad administrativa.

En materia de Seguridad y Salud en el Trabajo existen más de 30 resoluciones vigentes, dentro las que se destacan: la Resolución 1401 de 2007 que reglamenta la investigación de accidentes e incidentes de trabajo expedida por el Ministerio de la Protección Social, la Resolución 3673 de 2008 por la cual se establece el Reglamento Técnico de Trabajo Seguro en Alturas, la Resolución 1348 de 2009 establece el Reglamento de Salud Ocupacional en el sector eléctrico, la Resolución 312 de 2019 por la cual se definen los estándares mínimos del Sistema de Gestión en Seguridad y Salud en el Trabajo, entre otras.

\subsection{Circulares}

El Decreto 2304 de 1989 define las Circulares como el "acto administrativo por medio del cual el jefe de una dependencia oficial o unidad burocrática da órdenes o instrucciones a sus subalternos."

En materia de Seguridad y Salud del Trabajo dichas circulares en su mayoría provienen de la Dirección General de Riesgos Laborales, como una pauta de direccionamiento a los actores del sistema de riesgos profesionales. Un claro ejemplo que 
merece mención es la Circular Unificada de 2004 que tuvo por objeto unificar las instrucciones para la vigilancia, control y administración del entonces llamado Sistema General de Riesgos Profesionales.

\subsection{Jurisprudencia}

También, se encuentra como fuente la jurisprudencia que está conformada por el conjunto de sentencias judiciales, es decir por aquellos fallos de un juez o magistrado que ponen fin a un proceso.

La Corte Constitucional definió el significado de sentencia en los siguientes términos: "la sentencia, en cualquier proceso, es la decisión judicial más importante dictada por una autoridad del Estado, investida de jurisdicción, que no sólo debe cumplir los requisitos establecidos en la ley en cuanto a su forma y contenido, sino que constituye un juicio lógico y axiológico destinado a resolver una situación controversial, en armonía con la Constitución y la ley. Dicha providencia no es, entonces, un simple acto formal sino el producto del análisis conceptual, probatorio, sustantivo y procesal, de unos hechos sobre los cuales versa el proceso, y de las normas constitucionales y legales aplicables al caso concreto." (Corte Constitucional, C-252, 2001).

En tanto que la sentencia judicial entra a definir una situación controversial, la misma goza de fuerza vinculante, según el tipo de efecto que la misma produzca entre las partes.

Por lo anterior, es necesario distinguir que las sentencias judiciales, según el efecto que puedan producir, puede agruparse en tres grandes grupos: interpartes, erga omnes e interpares. Las sentencias interpartes serán cuando sólo produce efecto a las partes involucradas en el proceso, tal como sucede en las acciones de tutelas o sentencias tipo T. Las sentencias erga omnes o generales se generan cuando el efecto vincula a toda la población en general, por tanto, gozará de la misma fuerza del poder legislativo, pero en el sentido de expulsar del ordenamiento la norma que va en contra de la Constitución Política, tal como sucede en la sentencia de control de constitucionalidad o sentencias tipo C. Por último, las inter pares funcionarán como un dispositivo amplificador y por tanto el efecto de una decisión judicial podrá aplicarse en todos los casos similares frente a un problema jurídico en específico. (Corte Constitucional, Sentencia SU-037, 2019).

Tener conocimiento de las distintas sentencias judiciales en materia de Seguridad y Salud en el Trabajo delimitan en gran medida el actuar jurídico de las partes del Sistema General de Riesgos Laborales, las leyes no pueden prever todas las situaciones posibles y aún en el caso que lo hagan también existen problemas de interpretación, por ello corresponde a los organismos de cierre llenar los vacíos y fijar las pautas de interpretación de los problemas jurídicos.

Una sentencia que sirve como ejemplo y que a su vez es de gran importancia en materia de Seguridad y Salud en el Trabajo es la sentencia C-425 de 2015, la Corte Constitucional al decidir sobre la constitucionalidad del parágrafo $1^{\circ}$ del artículo 1 de la ley 776 de 2002, elevó el principio de primacía de la realidad sobre la formalidades en las relaciones laborales, al concluir que un artículo que prohíba el aumento del grado de incapacidad con base en patologías anteriores, está desconociendo la realidad física del trabajador y su invalidez material que merecen protección bajo los principios de igualdad, irrenunciabilidad, universalidad, solidaridad y obligatoriedad de la seguridad social. A partir de dicho pronunciamiento jurisprudencial, 
la calificación del grado de invalidez debe ser integral atendiendo así a la realidad física del trabajador e incluyendo patologías anteriores.

\subsection{Ordenanzas y Acuerdos}

Las ordenanzas y acuerdos son las disposiciones promulgadas por la corporación política- administrativa de elección popular ya sea asamblea departamental o por el concejo municipal y sus disposiciones serán obligatorias únicamente al departamento o municipio respectivamente.

Las anteriores competencias normativas, otorgadas a estas entidades territoriales, se encuentran limitadas respectivamente en los artículos 300 y 313 de la Constitución Política. Un ejemplo de Acuerdo que rige para el Distrito Capital es el Acuerdo 576 de 2014 por el cual se implementa el sistema de historia clínica electrónica en el distrito capital.

Por último se encuentra las normas internas de la empresa, dentro de la cual se encuentra el reglamento interno de trabajo.

\section{Antecedentes, definición y ventajas de la matriz legal}

El concepto de matriz legal, es un término reciente y utilizado en países como Colombia, Argentina y el Salvador para referirse al compendio de requisitos legales que debe seguir una empresa en materia de Seguridad y Salud en el Trabajo.

Como se mencionó anteriormente, en Colombia es un término que nace con la expedición del Decreto 1443 de 2014, por el cual se dictaron disposiciones para la implementación del Sistema de Gestión de la Seguridad y Salud en el trabajo (SG-SST), actualmente compilado en el capítulo 2.2.4.6 del Decreto 1072 de 2015.

El Decreto 1443 de 2014 tomó en consideración para su promulgación el cumplimiento del objetivo del Sistema de Riesgos Laborales, es decir, la obligación del gobierno nacional en promulgar normas técnicas tendientes a la seguridad de los trabajadores, asimismo la adopción, como país miembro de la Comunidad Andina, de la Decisión 584" Instrumento Andino de Seguridad y Salud en el Trabajo". Por último, la elaboración del mismo tuvo como guía las Directrices relativas a los Sistemas de Gestión de Seguridad y Salud en el Trabajo ILO OSH 2001 que son recomendaciones prácticas de elaboración de normas nacionales propuestas por la Organización Internacional del Trabajo OIT.

La ILO OSH 2001 desde su publicación se han convertido en un modelo ampliamente utilizado, traducido a 22 idiomas, utilizado en más de 30 países en la elaboración de normas nacionales en el tema de Seguridad y Salud en el Trabajo y reconocido formalmente por ser la directriz de mayor adaptabilidad en países como Argentina, Brasil, Israel e Irlanda. (OIT, 2011).

En sentido general, la matriz legal se entiende como el conjunto de normas a la cuales debe sujetarse las empresas o empleadores en materia de seguridad y salud en el trabajo.

El Decreto Único del Sector Trabajo es la normatividad que contiene el concepto de matriz legal y lo definió en su artículo 2.2.4.6.2 en los siguientes términos: "Es la compilación de los requisitos normativos exigibles a la empresa acorde con las actividades propias e inherentes de su actividad productiva, los cuales dan los 
lineamientos normativos y técnicos para desarrollar el Sistema de Gestión de la Seguridad y Salud en el Trabajo (SG-SST), el cual deberá actualizarse en la medida que sean emitidas nuevas disposiciones aplicables."(Ministerio del Trabajo, 2015). A su vez estableció que la matriz legal hace parte de los objetivos de la Política de Seguridad y Salud en el Trabajo y de la documentación obligatoria del SG-SST.

La inclusión del concepto de matriz legal es una herramienta de gestión que permite armonizar el conocimiento y actualización de los lineamientos normativos con la actividades en seguridad y salud en el trabajo. La Resolución 312 de 2019 incluyó la matriz legal como un ítem obligatorio a ser verificado en las empresas de más de 50 trabajadores clasificadas en riesgo I, II, III, IV y V y en las empresas de riesgo IV y V. No obstante, vale la pena resaltar que la inclusión de la matriz legal trae muchas ventajas sin importar la clase de empresa.

Es un instrumento que facilita la actuación de la organización en la prevención de accidentes y enfermedades laborales, pues en términos simples conocer la normatividad aplicable ayudará sin duda a capacitarse para la prevención de accidentes y enfermedades laborales. En Colombia, según cifras de la Subdirección de Riesgos Laborales del Ministerio de Salud y Protección Social durante el año 2019 cada día se presentaron 1.696 accidentes de trabajo, 24 enfermedades laborales y 1,3 muertes relacionadas con el trabajo. En total en el año 2019 se presentaron 481 muertes de trabajadores relacionadas con el trabajo.

Tabla 1. Indicadores Sistema General de Riesgos Laborales.

\begin{tabular}{ll}
\hline Año & 2019 \\
\hline Trabajadores afiliados & 10.528 .465 \\
\hline Empresas afiliadas & 882.382 \\
\hline Pensiones de invalidez pagadas & 3.680 \\
\hline Muertes calificadas como laborales & 481 \\
\hline Muertes ocurridas & 825 \\
\hline Incapacidades permanentes parciales pagadas & 14.662 \\
\hline Enfermedades calificadas como laborales & 8.665 \\
\hline Accidentes calificados como laborales & 619.086 \\
\hline Presuntos accidentes de trabajo & 679.883 \\
\hline
\end{tabular}

Ministerio de Salud (2020)

Asimismo, prevenir la ocurrencia de accidentes laborales y/o enfermedades laborales también evitará el acarreamiento de responsabilidad de tipo administrativa, laboral, civil y/o penal para la empresa.

La Ley 1610 de 2013 faculta a los inspectores de Trabajo y Seguridad Social en virtud de su función coactiva o de policía administrativa a sancionar con multas equivalentes al monto de uno (1) a cinco mil (5.000) veces el salario mínimo mensual vigente según la gravedad de la infracción o incluso la clausura del lugar de trabajo en las actividades de inspección, vigilancia y control. 
Desde la vigencia de la Ley 57 de 1915, en materia laboral, no se exige la demostración de la culpa del empleador para el reconocimiento de prestaciones asistenciales y económicas de los accidentes laborales. Dichas prestaciones, en principio se encuentra a cargo del empleador, pero este las traslada a cargo de la ARL a través del respectivo pago de cotización al Sistema de Riesgos Laboral, sólo en caso que el empleador no cumpla con lo anterior responderá por ellas con sus propios recursos.

Ahora bien, independiente del derecho al pago de prestaciones asistenciales (tratamiento médico, quirúrgico y de rehabilitación) y económicas (pago de incapacidad temporal, incapacidad permanente parcial, pensión de invalidez, de sobrevivientes y auxilio funerario), el trabajador o sus familiares en virtud del artículo 216 del Código Sustantivo del Trabajo tiene la posibilidad de demandar civilmente al empleador, en dicho caso sí se hace necesario la demostración de la culpa del empleador con miras a lograr un indemnización de perjuicios. En este punto, adquiere vital importancia la implementación de la matriz legal que da cuenta del cumplimento de sus responsabilidades y por ende la demostración de diligencia que permita la exoneración dentro de un proceso judicial por reparación plena de perjuicios.

Hoy en día, la prosperidad de una demanda de responsabilidad civil puede representar tanto un perjuicio económico, como también un riesgo reputacional para la empresa. Por ejemplo en Sentencia de la Corte Suprema de Justicia, en Sala Casación Laboral SL4570-2019 con numero de Radicación n. ${ }^{\circ}$ 78718, con Magistrada Ponente Clara Cecilia Dueñas Quevedo se resolvió condenar a la Sociedad Portuaria Río Córdoba a pagar la suma total de \$1.521.814.050 por concepto de lucro cesante, perjuicios morales y daño en la vida en relación a favor de la esposa, tres hijos y dieciséis hermanos de un trabajador que sufrió un accidente laboral mortal por la inobservancia de las normas en seguridad y salud en el trabajo. Lo anterior, puede estar cobijado por una póliza de responsabilidad civil, pero en caso que no cuente la empresa con dicha póliza incurrirá en un gasto considerable, que puede incluso significar la exposición a riesgo reputacional en el evento que llegue a representar un caso mediático.

Adicionalmente, si una empresa conoce y cumple las normas de seguridad y salud en el trabajo mejora sin duda el clima organizacional de la empresa, en el sentido que el trabajador percibe dicho cumplimento como el compromiso por parte de la alta dirección con su integridad, de modo que los trabajadores se sienten retribuidos en sus esfuerzos de contribuir con la productividad de la empresa.

\section{Los componentes de la matriz legal}

Para establecer la matriz legal de empresa es necesario tener presente que esta se integra de dos componentes, el primero es el componente legal y el segundo es el componente de cumplimiento y seguimiento. Lo anterior, está basado en el modelo mismo del SG- SST que no se trata de un simple proceso estableciendo pasos, sino que se entiende como un proceso dinámico, integrado e iterativo que exige la mejora en las actividades de la seguridad y salud en el trabajo en su conjunto. Para el caso del establecimiento de la matriz legal no se trata pues del mero ejercicio de compilar las normas de riesgo laboral, sino también de hacerle un seguimiento en cuanto a su cumplimiento y vigencia. 


\subsection{Componente legal.}

El componente legal estará conformado por todas las normas vigentes de riesgos laborales a las cuales debe sujetarse las empresas. Entonces, en primer lugar, se trata de un ejercicio de investigar y compilar dicha normatividad y a su vez diferenciarse en grupos, pues existen normas que puede aplicar a ciertas empresas, pero a otras no por el tipo de actividad que realizan o por el tipo de riesgo que enfrentan en el desarrollo de sus actividades y también habrá normas que las empresas decidan adoptar voluntariamente por el beneficio que estas representan. En tal sentido, se propone tres divisiones del componente legal: general, específico y potestativo.

Una vez se tenga la distinción de los tres componentes; es importante que cada norma que haga parte de la matriz legal de la empresa tenga claramente definido los siguientes descriptores en el siguiente orden; el titulo de la norma, la descripción de la norma que suele estar dado por el emisor, el articulado aplicable en materia de seguridad y salud en el trabajo y por último será importante especificar si dicha norma es o no de obligatorio cumplimiento.

\section{- Componente General}

El componente general estará conformado por la normatividad nacional vigente en materia de seguridad y salud en el trabajo que rigen para todos los empleadores y contratantes de personal a nivel nacional, sin importar el vínculo laboral que tengan con sus trabajadores.

Ahora bien, tal como se menciono anteriormente la norma de normas en nuestro ordenamiento jurídico es la Constitución Política, por tanto, toda norma en seguridad y salud en el trabajo debe estar acorde a la misma.

La normativa principal que rige la relación entre empleador y trabajador es el Código Sustantivo de Trabajo, que compiló el Decreto 2663 de 1950 y el Decreto 3743 de 1950. Si bien en su capítulo II del Título VIII regula lo concerniente a accidentes de trabajos y enfermedades, el mismo ha sido reformado por varias leyes. Por lo anterior, resulta importante conocer cuáles han sido las leyes más representativas en materias de seguridad y salud en el trabajo, aunque en principio fue una reglamentación incipiente y llamada de distinta manera, a saber: Programa de Salud Ocupacional.

La Ley 9 de 1979, lo que hoy se conoce como el Código Nacional Sanitario, fue la primera normatividad que reglamentó la Salud Ocupacional. Dicha ley, en su Título III expuso el objeto de la Salud Ocupacional en cinco sentidos: la prevención de todo daño derivado de las condiciones laborales, la protección contra riesgos, la eliminación y el control de los agentes perjudiciales, la protección especial de personas expuestas a radiaciones y protección a sustancias peligrosas. Asimismo, definió escuetamente el Programa de Salud Ocupacional como aquel programa que contemplara las actividades destinadas a la prevención tanto de los accidentes como enfermedades relacionadas con el trabajo, con la responsabilidad de crear comités de medicina, higiene y seguridad industrial con participación tanto de trabajadores como empleadores. Esta ley facultó al Ministerio de Salud, hoy en día Ministerio de Salud y Protección Social, como el ente encargado de organización y funcionamiento de dichos asuntos, pero con la Ley 1444 de 2011, pasó a cargo del Ministerio de Trabajo. 
Fue el Decreto 614 de 1984, actualmente derogado, en sus artículos 28, 29 y 30, el que estableció por primera vez la obligatoriedad de adelantar los Programas de Salud Ocupacional, en dicha normatividad se sentaron las bases para la organización y administración de la Salud Ocupacional en el país.

Posteriormente vino a regir la Resolución 1016 de 1989, que estuvo vigente hasta el 31 de marzo de 2017, reglamentó oficialmente la organización, funcionamiento y forma de Salud Ocupacional. Esta resolución fue más integral e incluyó subprogramas en la salud ocupacional: Medicina Preventiva, Medicina del Trabajo, Higiene Industrial y Seguridad Industrial.

Ley 100 de 1993, como se mencionó anteriormente es la ley que creo el Sistema General de la Seguridad Social y que a su vez creo el Sistema General de Riesgos Profesionales, si bien no sentó sus fundamentos mínimos en su articulo 139 revistió de facultades extraordinarias al Presidente de la Republica para establecer DecretoLey 1295 de 1994 (Ayala, 2004-2005). Dicho decreto finalmente y por primera vez establece la organización y administración del Sistema de Riesgos Laborales.

La Ley 1562 de 2012, conocida como la Ley de Riesgos Laborales, le dio un nuevo giro a este sistema e incorporó un concepto más amplio de Salud Ocupacional en el siguiente sentido: "...disciplina que trata de prevenir las lesiones y enfermedades causadas por las condiciones de trabajo y la protección y promoción de la salud de los trabajadores. Tiene por objeto mejorar las condiciones y el medio ambiente de trabajo, así como la salud en el trabajo, que conlleva la promoción y el mantenimiento del bienestar físico, mental y social de los trabajadores en todas las ocupaciones." (Ley 1562, 2012, art. 1).

En este contexto, se empezó a hablar de Sistema de Gestión de la Seguridad y Salud en el trabajo SG-SST, como el término que reemplazó el Programa de Salud Ocupacional. Dicha sustitución no sólo fue semántica, sino también la ventaja de aplicar un enfoque más útil y sistemático, puesto que facilita la aplicación de un método eficaz de gestión de peligros y riesgos que integre tanto la evaluación como el mejoramiento de los resultados en la prevención de incidentes y accidentes en el lugar del trabajo. Es importante anotar que tal decisión se vio también impulsada por el éxito de las normas técnicas ISO 9000 e ISO 14000 del sistema de gestión en calidad y medio ambiente respectivamente.

El Decreto 1443 de 2014 fue el instrumento legal que incorporó por primera vez el concepto de matriz legal en la implementación del SG-SST en Colombia. Dicho decreto fue el encargado de dictar las disposiciones concernientes a la implementación del SG-SST.

Posteriormente, el Decreto Único Reglamentario del Sector Trabajo 1072 del año 2015, en su propósito de compilar y racionalizar las reglamentaciones en materia laboral, en su Libro 2, Parte 2, Titulo 4, Capitulo 6, compila los artículos del Decreto 1443 de 2014 y por tanto deroga esa norma como contenido independiente y su vez compila la mayoría de decretos referentes a esta materia.

Finalmente se encuentra la Resolución 312 de 2019 que estableció los Estándares Mínimos en el Sistema de Gestión de SST, derogando la Resolución 1111 de 2017. estableciendo "el conjunto de normas, requisitos y procedimientos de obligatorio cumplimiento de los empleadores y contratantes, mediante los cuales se establecen, 
verifican y controlan las condiciones básicas de capacidad técnico-administrativa y de suficiencia patrimonial y financiera indispensables para el funcionamiento, ejercicio y desarrollo de actividades en el Sistema de Gestión de SST".

La implementación de estándares mínimos ha sido parte de una evolución normativa compleja. En un comienzo el cumplimiento del Programa de Salud Ocupacional en las empresas, era asumido de forma independiente por parte de la Aseguradoras de Riesgos Laborales con listas de chequeos bajo un conjunto de criterios establecidos por las mismas. Posteriormente, con la expedición de la Resolución 1111 de 2017 se estableció un articulado complejo y un anexo técnico aplicable a todas las empresas con la exigencia de 62 estándares mínimos sin la distinción del sector productivo o número de trabajadores lo que se traducía en mayores e innecesarios costos y requisitos para las empresas. Finalmente, la Resolución 312 de 2019 cuenta con la debida distinción del sector y riesgo de las empresas y número de trabajadores de las mismas e incluyó la obligatoriedad de la matriz legal como parte de los estándares mínimos para aquellas empresas de más de cincuenta trabajadores clasificadas con riegos I, II, III, IV y V y para las empresas de riesgo IV y V sin importar su número de trabajadores. A continuación, se expone un ejemplo de cómo articular el componente legal.

Tabla 2. Componente Legal de la matriz legal.

\begin{tabular}{|c|c|c|c|c|}
\hline \multicolumn{2}{|c|}{ Componente general } & \multirow[b]{2}{*}{ Articulado } & \multicolumn{2}{|c|}{ Obligatorio } \\
\hline Norma & Descripción & & Si & No \\
\hline CST & $\begin{array}{l}\text { Regula la relación entre empleadores } \\
\text { y trabajadores }\end{array}$ & Tít. VII (II) IX (II) XI & $x$ & \\
\hline Ley 9 de 1979 & Dicta medidas sanitarias & Título III & $x$ & \\
\hline Ley 100 de 1993 & $\begin{array}{l}\text { Crea el sistema de seguridad social } \\
\text { integral }\end{array}$ & Libro III & $x$ & \\
\hline Ley 181 de 1995 & Fomento de recreación y deporte & art. 23 & $x$ & \\
\hline Ley 797 de 2003 & $\begin{array}{l}\text { Disposiciones del Sistema General de } \\
\text { Pensiones }\end{array}$ & & $x$ & \\
\hline Ley 1010 de 2006 & Ley de Acoso Laboral & & $x$ & \\
\hline Ley 1335 de 2009 & Prevención y Consumo de tabaco & articulo 20 & $x$ & \\
\hline Ley 776 de 2012 & $\begin{array}{l}\text { Ley Sistema General de Riesgos } \\
\text { Profesionales }\end{array}$ & & $x$ & \\
\hline Ley 1616 de 2012 & Ley Nacional de Salud Mental & articulo. 9 & $x$ & \\
\hline Ley 1523 de 2012 & $\begin{array}{l}\text { Adopta la política nacional de gestión } \\
\text { del riesgo de desastres }\end{array}$ & & $x$ & \\
\hline Ley 1562 de 2012 & $\begin{array}{l}\text { Modifican el Sistema de Riesgos } \\
\text { Profesionales }\end{array}$ & & $x$ & \\
\hline Dec-Ley 1295 de 1994 & $\begin{array}{l}\text { Organización y administración del } \\
\text { SGRP }\end{array}$ & & $x$ & \\
\hline Decreto 1108 de 1994 & $\begin{array}{l}\text { Reglamenta estupefacientes y } \\
\text { sustancias psicotrópicas }\end{array}$ & capitulo IX & $x$ & \\
\hline Decreto 2644 de 1994 & $\begin{array}{l}\text { Expide Tabla única para las } \\
\text { indemnizaciones por PCL }\end{array}$ & & $x$ & \\
\hline Decreto 1607 de 2002 & $\begin{array}{l}\text { Tabla de Clasificación de Actividades } \\
\text { Económicas SGRP }\end{array}$ & & $x$ & \\
\hline Decreto 1477 de 2014 & Tabla de enfermedades laborales & & $x$ & \\
\hline Decreto 19 de 2012 & Ley Anti-trámite & & $x$ & \\
\hline
\end{tabular}




\begin{tabular}{|c|c|c|c|c|}
\hline \multicolumn{2}{|c|}{ Componente general } & \multirow[b]{2}{*}{ Articulado } & \multicolumn{2}{|c|}{ Obligatorio } \\
\hline Norma & Descripción & & Si & No \\
\hline DUR 1072 DE 2015 & $\begin{array}{l}\text { Decreto único Reglamentario del } \\
\text { Sector Trabajo }\end{array}$ & Libro 2 Titulo 4-5 & $x$ & \\
\hline DUR 780 de 2016 & $\begin{array}{l}\text { Decreto único Reglamentario del } \\
\text { Sector Salud }\end{array}$ & Libro 2 Parte 2 & $x$ & \\
\hline Decreto 2157 de 2017 & $\begin{array}{l}\text { Directrices generales del plan de } \\
\text { gestión del riesgo de desastres }\end{array}$ & art. 23 & $x$ & \\
\hline Decreto 676 de 2020 & $\begin{array}{l}\text { Incorporación enfermedad a Tabla de } \\
\text { enfermedades Laborales }\end{array}$ & & & \\
\hline $\begin{array}{l}\text { Resolución } 2400 \text { de } \\
1979\end{array}$ & $\begin{array}{l}\text { Disposiciones sobre vivienda, higiene } \\
\text { y seguridad }\end{array}$ & & $x$ & \\
\hline $\begin{array}{l}\text { Resolución } 2013 \text { de } \\
1986\end{array}$ & $\begin{array}{l}\text { Reglamenta Comités Paritarios de } \\
\text { SST }\end{array}$ & & $x$ & \\
\hline $\begin{array}{l}\text { Resolución } 2346 \text { de } \\
2007\end{array}$ & $\begin{array}{l}\text { Metodología de los exámenes } \\
\text { médicos ocupacionales }\end{array}$ & & $x$ & \\
\hline $\begin{array}{l}\text { Resolución } 1401 \text { de } \\
2007\end{array}$ & $\begin{array}{l}\text { Reglamenta investigación de } \\
\text { incidentes y accidentes de trabajo }\end{array}$ & & $x$ & \\
\hline Resolución 652 de 2012 & $\begin{array}{l}\text { Reglamenta Comité de convivencia } \\
\text { Laborales }\end{array}$ & & $x$ & \\
\hline Resolución 666 de 2020 & Protocolo bioseguridad para COVID & & $x$ & \\
\hline Resolución 223 de 2021 & $\begin{array}{l}\text { Modifica anexo técnico del Protocolo } \\
\text { COVID }\end{array}$ & & & \\
\hline Resolución 391 de 2022 & Modifica Protocolo COVID & & & \\
\hline Circula 2004 & $\begin{array}{l}\text { Vigilancia, control y administración } \\
\text { del SGRP }\end{array}$ & & $x$ & \\
\hline Circular 0038 & $\begin{array}{l}\text { Reglamenta espacios libres de humo } \\
\text { y (SPA) en las Empresas }\end{array}$ & & $x$ & \\
\hline
\end{tabular}

Elaboración de la autora.

Nota: Se incluyen las normas que rigen para todas las empresas en materia de seguridad y salud en el trabajo. Es importante dar una pequeña descripción de las normas y distinguir cuales de sus artículos aplican, puesto que habrán normas que por su contenido general no aplicará de manera integral. Asimismo será de carácter obligatorio para todas las empresas.

\section{Componente especifico}

El componente especifico abarcará la normatividad de acuerdo a la actividad económica que desarrolle la empresa o también llamadas normas sectoriales, los riesgos identificados y las normas territoriales dependiendo del lugar donde la empresa desarrolle sus actividades.

En primer lugar, hay que distinguir las normas sectoriales dependiendo de las actividades económicas que desarrolle la empresa, vale entonces la pena distinguir el sector de minería, atención en salud humana, el sector de servicios de vigilancia, el sector transporte, el sector de la construcción y el sector comercio. En segundo lugar, es indispensable identificar los riesgos a los que se encuentra expuesta la organización en materia de seguridad y salud en el trabajo, siendo los mas recurrentes; el riesgo eléctrico, el trabajo en altura, el ruido, el trabajo en espacios confinados y el manejo de productos químicos. En este punto, resulta ser de gran utilidad la matriz de riesgos. Por último, en Colombia en materia de seguridad y salud en el trabajo se ha legislado de forma especial a los estudiantes, la actividad de Teletrabajo, las empresas de servicios temporales y las actividades de alto riesgo. 
Ahora bien, este componente debe estar ajustado a la normatividad vigente, para citar un claro y reciente ejemplo es que los empleadores con la expedición del Decreto Legislativo 417 del 17 de marzo de 2020 que declaró el estado de emergencia social, económica y ecológica, se vieron obligados a ajustar el ejercicio de sus actividades a la implementación de una normatividad en materia de seguridad al trabajo relacionada al nuevo coronavirus COVID 19. Es así, que se dictaron medidas orden nacional aplicables a todos los empleadores como es la Resolución 666 de 2020, por parte de Ministerio de Salud y Protección Social, que dicto el Protocolo General de Bioseguridad aplicable a todos los empleadores, la circular 0017 del 24 de febrero de 2020, por parte del Ministerio de Trabajo, que fijó los lineamientos mínimos a implementar de promoción y prevención para la preparación, respuesta y atención de casos de enfermedad por COVID -19 y la Circular Externa 018 de 2020 referente a instrucciones de intervención, respuesta y atención del Covid-19. Igualmente, el Ministerio de Salud y Protección Social expidió paulatinamente los protocolos de bioseguridad para el manejo y control del riesgo de coronavirus COVID-19 para cada uno de los sectores o actividades económicas.

A continuación, un ejemplo del componente especifico, en el que se abarcan algunos de los más destacados sectores económicos dependiendo del tipo de actividad que desarrolle la empresa se escogerá el mismo:

Tabla 2. Componente Especifico por el sector económico de la empresa.

\begin{tabular}{|c|c|c|c|c|}
\hline \multicolumn{3}{|c|}{ Componente especifico por sectores } & \multicolumn{2}{|c|}{ Obligatorio } \\
\hline Norma & Descripción & Artículo & Si & No \\
\hline \multicolumn{5}{|c|}{ Minero } \\
\hline Decreto 2222 de 1993 & $\begin{array}{l}\text { Reglamento de higiene y seguridad de } \\
\text { labores mineras }\end{array}$ & & $x$ & \\
\hline Decreto 035 de 1994 & $\begin{array}{l}\text { Disposiciones en materia de Seguridad } \\
\text { Minera }\end{array}$ & & $x$ & \\
\hline Ley 685 de 2001 & Código de Minas & & $x$ & \\
\hline Decreto 1886 de 2015 & $\begin{array}{l}\text { Reglamento en las Labores mineras } \\
\text { Subterráneas }\end{array}$ & & $x$ & \\
\hline $\begin{array}{l}\text { Resolución } 797 \text { de } \\
2020\end{array}$ & $\begin{array}{l}\text { Protocolo Bioseguridad COVID } 19 \text { para el } \\
\text { sector minas y energía }\end{array}$ & & $x$ & \\
\hline \multicolumn{5}{|c|}{ Atención en salud } \\
\hline Ley 1831 de 2017 & $\begin{array}{l}\text { Obligatoriedad Desfibrilador Externo } \\
\text { Automático (DEA) }\end{array}$ & & $x$ & \\
\hline Decreto 2676 de 2000 & Gestión integral para residuos hospitalarios & & $x$ & \\
\hline $\begin{array}{l}\text { Resolución } 482 \text { de } \\
2018\end{array}$ & $\begin{array}{l}\text { Reglamenta el uso de equipos generadores } \\
\text { de radiación ionizante }\end{array}$ & & $x$ & \\
\hline $\begin{array}{l}\text { Resolución } 1155 \text { de } \\
2020\end{array}$ & $\begin{array}{l}\text { Protocolo Bioseguridad COVID } 19 \text { para el } \\
\text { sector salud }\end{array}$ & & $x$ & \\
\hline \multicolumn{5}{|c|}{ Vigilancia } \\
\hline Ley 1539 de 2012 & Ley del Vigilante & & $x$ & \\
\hline Decreto 2368 de 2012 & $\begin{array}{l}\text { Requisitos de permiso para tenencia y porte } \\
\text { de armas de fuego }\end{array}$ & & $x$ & \\
\hline Decreto 738 de 2013 & $\begin{array}{l}\text { Aptitud psicofísica para porte de armas de } \\
\text { fuego }\end{array}$ & & $x$ & \\
\hline Decreto 026 de 2017 & Sistema Integrado de Seguridad & & $x$ & \\
\hline
\end{tabular}


Componente especifico por sectores

Obligatorio

\begin{tabular}{|c|c|c|c|c|}
\hline \multicolumn{3}{|c|}{ Componente especifico por sectores } & \multicolumn{2}{|c|}{ Obligatorio } \\
\hline Norma & Descripción & Artículo & Si & No \\
\hline \multicolumn{5}{|c|}{ Transporte } \\
\hline Ley 1503 de 2011 & $\begin{array}{l}\text { Hábitos, comportamientos y conductas } \\
\text { seguros en las vías }\end{array}$ & & $x$ & \\
\hline Decreto 1609 de 2002 & $\begin{array}{l}\text { Manejo y transporte terrestre de mercancías } \\
\text { peligrosas }\end{array}$ & & $x$ & \\
\hline Decreto 034 de 2009 & $\begin{array}{l}\text { Condicione tránsito de vehículos de carga en } \\
\text { el área urbana }\end{array}$ & & $x$ & \\
\hline Decreto 2851 de 2013 & Reglamenta Ley 1503 de 2011 & & $x$ & \\
\hline Decreto 602 de 2017 & $\begin{array}{l}\text { Gestión de Riesgo de Desastres, para el } \\
\text { sector transporte }\end{array}$ & & $x$ & \\
\hline $\begin{array}{l}\text { Resolución } 1565 \text { de } \\
2014\end{array}$ & $\begin{array}{l}\text { guía metodológica del Plan estratégico de } \\
\text { Seguridad Vial }\end{array}$ & & $x$ & \\
\hline $\begin{array}{l}\text { Resolución } 677 \text { de } \\
2020\end{array}$ & $\begin{array}{l}\text { Protocolo de bioseguridad para el sector } \\
\text { transporte }\end{array}$ & & $x$ & \\
\hline $\begin{array}{l}\text { Resolución } 904 \text { de } \\
2020\end{array}$ & $\begin{array}{l}\text { Protocolo de bioseguridad para el sector } \\
\text { portuario }\end{array}$ & & $x$ & \\
\hline Circular 068 de 2017 & $\begin{array}{l}\text { revisión de los Planes Estratégicos de } \\
\text { Seguridad Vial }\end{array}$ & & $x$ & \\
\hline \multicolumn{5}{|c|}{ Construcción } \\
\hline Circular 001 de 2020 & Orientaciones COVID-19 sector construcción & & $x$ & \\
\hline Decreto 1972 de 1995 & $\begin{array}{l}\text { Convenio sobre la seguridad y salud en la } \\
\text { construcción }\end{array}$ & & $x$ & \\
\hline $\begin{array}{l}\text { Resolución } 2413 \\
\text { de1979 }\end{array}$ & $\begin{array}{l}\text { Reglamento de higiene y seguridad } \\
\text { industrial en construcción }\end{array}$ & & $x$ & \\
\hline $\begin{array}{l}\text { Resolución } 898 \text { de } \\
2020\end{array}$ & $\begin{array}{l}\text { Protocolo de bioseguridad COVID-19 obras } \\
\text { habitadas }\end{array}$ & & $x$ & \\
\hline $\begin{array}{l}\text { Resolución } 682 \text { de } \\
2020\end{array}$ & $\begin{array}{l}\text { Protocolo de bioseguridad COVID-19 de } \\
\text { edificaciones }\end{array}$ & & $x$ & \\
\hline \multicolumn{5}{|c|}{ Comercio } \\
\hline Ley 1831 de 2017 & $\begin{array}{l}\text { Obligatoriedad Desfibrilador Externo } \\
\text { Automático (DEA) }\end{array}$ & & $x$ & \\
\hline $\begin{array}{l}\text { Acuerdo Distrital } \\
230 / 2006\end{array}$ & $\begin{array}{l}\text { botiquín en los establecimientos de } \\
\text { comercio }\end{array}$ & & $x$ & \\
\hline
\end{tabular}

Elaboración de la autora.

Ahora bien, una vez se cuenta con la distinción dentro la cuál la empresa desarrolla sus actividades, el empleador deberá identificar los peligros a los que en encuentra expuesto el trabajador en su entorno laboral, es decir con aquellas situaciones que poseen la potencialidad de producir un daño, con el fin de determinar la normatividad aplicable. Lo anterior, se precisa con la ayuda de la implementación de la matriz de riesgos.

A continuación, se expone un ejemplo del componente especifico de acuerdo con los peligros más comunes, sin decir que sean los únicos a los que se encuentran expuestos los trabajadores en sus entornos laborales. 
Tabla 3. Componente Especifico por los peligros de la empresa.

\begin{tabular}{|c|c|c|c|c|}
\hline \multicolumn{3}{|c|}{ Componente específico por peligros } & \multicolumn{2}{|c|}{ Obligatorio } \\
\hline Norma & Descripción & Artículo & Si & No \\
\hline \multicolumn{5}{|c|}{ Iluminación } \\
\hline $\begin{array}{l}\text { Resolución } 1800540 \\
\text { de } 2010\end{array}$ & $\begin{array}{l}\text { Reglamento Técnico de Iluminación y } \\
\text { Alumbrado público RETILAP }\end{array}$ & & $x$ & \\
\hline \multicolumn{5}{|c|}{ Eléctrico } \\
\hline Ley 1264 de 2008 & Código de Ética de técnico s electricistas & & $x$ & \\
\hline \multicolumn{5}{|c|}{ Trabajo en alturas } \\
\hline $\begin{array}{l}\text { Resolución } 3673 \text { de } \\
2008\end{array}$ & $\begin{array}{l}\text { Reglamento técnico de trabajo seguro en } \\
\text { alturas }\end{array}$ & & $x$ & \\
\hline $\begin{array}{l}\text { Resolución } 736 \text { DE } \\
2009\end{array}$ & $\begin{array}{l}\text { Modifica el Reglamento técnico de trabajo } \\
\text { seguro en alturas }\end{array}$ & & $x$ & \\
\hline $\begin{array}{l}\text { Resolución } 1409 \text { de } \\
2012\end{array}$ & $\begin{array}{l}\text { Procedimientos e instrucciones para trabajo } \\
\text { en alturas }\end{array}$ & & $x$ & \\
\hline $\begin{array}{l}\text { Resolución } 1903 \text { de } \\
2013\end{array}$ & Capacitación sobre trabajo seguro en alturas & & $x$ & \\
\hline $\begin{array}{l}\text { Resolución } 1178 \text { de } \\
2017\end{array}$ & $\begin{array}{l}\text { Requisitos técnicos y de seguridad Caídas en } \\
\text { Trabajo en Alturas }\end{array}$ & & $x$ & \\
\hline $\begin{array}{l}\text { Resolución } 3368 \text { de } \\
2014\end{array}$ & Reglamenta coordinador y entrenador & & $x$ & \\
\hline $\begin{array}{l}\text { Resolución } 1248 \text { de } \\
2020\end{array}$ & Medidas transitorias frente COVID-19 & & $x$ & \\
\hline Circular 070 de 2009 & $\begin{array}{l}\text { Procedimientos e instrucciones para trabajo } \\
\text { en alturas }\end{array}$ & & $x$ & \\
\hline \multicolumn{5}{|c|}{ Ruido } \\
\hline $\begin{array}{l}\text { Resolución } 8321 \text { de } \\
1983\end{array}$ & $\begin{array}{l}\text { Normas de protección y conservación de } \\
\text { audición }\end{array}$ & & $x$ & \\
\hline $\begin{array}{l}\text { Resolución } 1792 \text { de } \\
1990\end{array}$ & $\begin{array}{l}\text { Valores límites permisibles para la } \\
\text { exposición ocupacional al ruido }\end{array}$ & & $x$ & \\
\hline Decreto 948 de 1995 & $\begin{array}{l}\text { Reglamento de protección y control de } \\
\text { calidad del aire }\end{array}$ & & $x$ & \\
\hline \multicolumn{5}{|c|}{ Trabajo en espacios confinados } \\
\hline $\begin{array}{l}\text { Resolución } 491 \text { de } \\
2020\end{array}$ & $\begin{array}{l}\text { Requisitos mínimos de seguridad de trabajos } \\
\text { en espacios confinados }\end{array}$ & & $x$ & \\
\hline $\begin{array}{l}\text { Resolución } 1348 \text { de } \\
2009\end{array}$ & $\begin{array}{l}\text { Reglamento de salud ocupacional sector } \\
\text { eléctrico }\end{array}$ & & $x$ & \\
\hline \multicolumn{5}{|c|}{ Productos químicos } \\
\hline Ley 55 de 1993 & $\begin{array}{l}\text { Seguridad en la utilización de productos } \\
\text { químicos en el trabajo }\end{array}$ & & $x$ & \\
\hline Decreto 1274 de 1997 & $\begin{array}{l}\text { Protección contra los riesgos de intoxicación } \\
\text { por el benceno }\end{array}$ & & $x$ & \\
\hline Decreto 1607 de 2002 & $\begin{array}{l}\text { Manejo y transporte terrestre de mercancías } \\
\text { peligrosas }\end{array}$ & & $x$ & \\
\hline Decreto 1496 de 2018 & $\begin{array}{l}\text { Sistema Globalmente Armonizado de } \\
\text { Clasificación y Etiquetado }\end{array}$ & & $x$ & \\
\hline $\begin{array}{l}\text { Resolución } 1013 \text { de } \\
2008\end{array}$ & $\begin{array}{l}\text { Salud Ocupacional basadas en la evidencia } \\
\text { para asma ocupacional }\end{array}$ & & $x$ & \\
\hline
\end{tabular}




\section{Componente potestativo}

Son aquellas normas que la empresa decide acoger voluntariamente en razón a cumplir con estándares nacionales o internacionales de certificación en materia de seguridad y salud en el trabajo.

En Colombia el organismo nacional de normalización es el Instituto Colombiano de Normas Técnicas y Certificación INCOTEC, entendiendo normalización como la actividad que establece disposiciones para uso común y repetido encaminadas al logro del grado óptimo de orden con respecto a problemas reales o potenciales en un contexto dado (DUR 1074 de 2015,Artículo 2.2.1.7.2.1 )El INCONTEC es un ente privado, sin ánimo de lucro, cuya misión fundamental es brindar soporte y desarrollo al productor y protección al consumidor, para logar ventajas competitivas en el mercado interno y externo. (Icontec), asimismo con la labor del Consejo Colombiano de Seguridad que ha establecido la Guía del Sistema de Seguridad, Salud en el Trabajo y Ambiente para Contratistas Ruc ${ }^{\circledR}$ dirigido principalmente al sector hidrocarburos.

A nivel internacional se encuentran las normas ISO, por sus siglas en inglés International Organization for Standardization, dedicada a la creación de estándares para asegurar la calidad, seguridad y eficiencia de productos y servicios. La ISO es una organización no gubernamental e independiente creada en 1947 que cuenta con 162 países miembros, a la fecha ha publicado alrededor de 22.432 estándares internacionales en materias de industria y tecnologías. (ISO, s.f.)

Tabla 4. Componente potestativo.

\begin{tabular}{|c|c|c|c|}
\hline \multicolumn{4}{|c|}{ Componente potestativo } \\
\hline Norma & Descripción & Articulo & Obligatorio \\
\hline ISO 4500012008 & Implementación del SG SST ISO & & \\
\hline ILO OSH 2001 & Directrices relativas a los SG SST por OIT & & \\
\hline RUC & $\begin{array}{l}\text { SG en Seguridad, Salud Ocupacional y } \\
\text { Medio Ambiente por CCS }\end{array}$ & & \\
\hline
\end{tabular}

Elaboración de la autora.

Componente de Evidencia de cumplimiento y seguimiento

Luego de investigar y compilar la normatividad aplicable a la empresa, se espera que estos sean sometidos a evaluación y seguimiento en su cumplimento por parte de la empresa.

La observancia de este componente es la materialización de la intención del legislador en materia de Seguridad y Salud en el Trabajo, y por tanto que el responsable no haga un mero ejercicio de compilación si no que además evalúe el cumplimiento de los requisitos normativos a los cuales esta obligada la empresa.

Lo anterior parte del principio de mejoramiento continuo del SG SST, basado en el ciclo PHVA o ciclo Deming, propuesto por el académico y profesor estadounidense Edwards Deming en la década de los cincuenta con base en los conceptos de su mentor Walter Shewhart. Deming propuso un proceso sistemático de cuatro pasos (Planear-Hacer-Verificar-Actuar) para la mejora continua de cualquier producto, proceso o servicio. Estos cuatros pasos llevan a pensar a que dicho ciclo no es una 
simple enunciación de lista de tareas por cumplir, sino un procedimiento lógico y por etapas que permiten el mejoramiento continuo a través de los cuatros pasos: planear, hacer, verificar y actuar. (The W. Edwards Deming Institute, 2020)

En tal sentido, la primera etapa involucra identificar los objetivos y el cómo llegar a ellos (PLANIFICAR), posteriormente se ejecutará los componentes de lo planeado (HACER), consecuentemente será necesario comprobar que lo ejecutado esté conforme a los objetivos planeados a través del seguimiento y medición (VERIFICAR), por último, la etapa en donde hay lugar a las acciones de mejoras con base en los resultados de las tres etapas anteriores.

Para dicho propósito, se hace necesario que se incluya tanto la verificación como la evaluación del cumplimiento del requisito normativo, y se incluyan los siguientes cuatro criterios: el primero será distinguir el actor o actores responsables de la ejecución del requisito normativo, una vez establecido lo anterior se tendrá que verificar que las actuaciones de la empresa estén en plena armonía con lo estipulado en dicho requisito normativo. En este punto se tendrá que partir de un criterio riguroso e integral en el sentido que su respuesta de cumplimiento sólo está enmarcado en dos respuestas de afirmación o negación, pues el anterior análisis llevará al último criterio que es la acción de mejora, indicando que en caso de incumplimiento el responsable deberá llevar a cabo las acciones de optimización correspondiente.

Tabla 5. Componente de evidencia de cumplimiento.

\begin{tabular}{ccccc}
\hline \multicolumn{4}{c}{ Componente de evidencia de cumplimiento } \\
\hline Actor responsable & Cumplimiento & Acción de mejora \\
Nombre, firma y Cargo & SI & NO & Fecha y Acción de Mejora \\
\hline
\end{tabular}

Elaboración de la autora.

Finalmente, la matriz legal se trata de la articulación de los dos componentes, del legal y de la evidencia de cumplimiento de la siguiente manera:

Tabla 6. Matriz Legal.

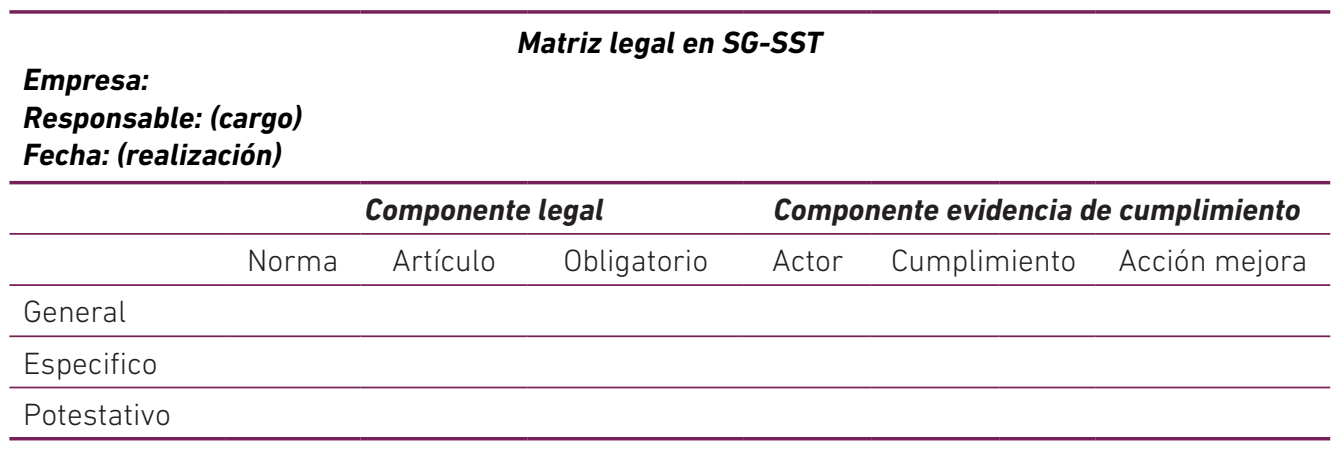




\section{Conclusiones}

Si bien con la expedición de la Resolución 312 de 2019 la matriz legal pasa a ser un estándar mínimo de cumplimiento sólo para ciertas empresas, basta con indicar que la normatividad en riesgos laborales hace parte intrínsecamente del Sistema de Gestión en SST de cualquier empresa bajo el entendido que toda empresa sin importar el lugar, actividad económica, riesgos o números de trabajadores debe sujetarse a las normas de seguridad y salud en el trabajo vigentes en aras de prevenir accidentes y enfermedades laborales.

Igualmente, lo anterior redunda en resultados positivos que optimizan los procesos de la empresa no sólo en las condiciones de salud y seguridad de los trabadores sino también representan un impacto favorable en términos de económicos para las empresas.

Ahora bien, lo más importante de plantear la matriz legal en el SG-SST es que sus componentes resulten fáciles de articular, por tanto, resulta importante señalar que sus aspectos deben estar claros y concisos, además que se presenten de una forma ordenada, para lo cual la matriz legal es un documento no sólo idóneo sino necesario en la búsqueda de tal fin.

La matriz legal al ser parte de la documentación obligatoria es indispensable que se plantee de forma entendible tanto para el responsable como para personal que eventualmente, como el caso de los inspectores de trabajo, que lleven a cabo una investigación administrativa.

\section{Bibliografia}

Arango, M. (2004). El Bloque de Constitucionalidad en la Jurisprudencia de la Corte Constitucional Colombiana. Recuperado de: http://www.icesi.edu.co/contenido/ pdfs/03.pdf.

Ayala, L. C. (2004-2005). Legislación en Salud Ocupacional y Riesgos Profesionales. Bogotá D.C: Ediciones Salud Laboral LTDA.

Castro, J. J. (1950).Tratado de Derecho Administrativo , Bogotá D.C: Editorial Argra.

Constitución Política de Colombia. [Const.]. 1ra Edición. Panamericana Editorial.

González, A. (2015). Undécima Edición. Introducción al Derecho. Bogotá, D.C: Librería ediciones del profesional Ltda.

Kelsen, H. Trad. (1982). Teoría Pura del derecho. Universidad Nacional Autónoma de México. Recuperado de: https://www.google.com.co/url?sa=t\&rct=$j \& q=\& e s r c=s \&$ source $=$ web \& $c d=\& v e d=2 a h \cup K E w i m o c \quad B v J n t A h X I Y d-$ 8KHWdrA gQFiAAegQIAxAC\&url=https\%3A\%2F\%2Faulavirtual4.unl.edu. ar\%2Fpluginfile.php \% 2F 7570\%2Fmod folder\%2Fcontent $\% 2$ F0\%2FTeor\%25C3\%25ADa\%2520pura\%2520del\%2520Derecho\%2520\%2520Kelsen. pdf\%3Fforcedownload\%3D1\&usg=AOvVaw3 bkUtu4ladbzBMWROTSdB.

Martínez, C (2010). Tipos de sentencias en el control constitucional de las leyes: La experiencia Colombiana. Estudios Socio Jurídicos. 2(1). Recuperado de: https:// revistas.urosario.edu.co/index.php/sociojuridicos/article/view/177. 
Ministerio del Trabajo. Cartilla para la Implementación del Sistema de Gestión de la Seguridad y Salud en el Trabajo (SG-SST) en las empresas.

OIT. (2011). Sistema de gestión de la SST: una herramienta para la mejora continua. Recuperado de: https://www.ilo.org/wcmsp5/groups/public/---ed protect/--protrav/---safework/documents/publication/wcms 154127.pdf.

OIT. (2011). Comparación Internacional de Sistemas de Salud y seguridad Laboral. . Recuperado de: https://www.ilo.org/wcmsp5/groups/public/---americas/---rolima/---sro-santiago/documents/publication/wcms 178071.pdf.

Plazas, G. (2018). La nueva seguridad social 2018.2019(Información actualizada sobre temas de Seguridad Social y seguridad y Salud en el Trabajo. Bogotá: Editorial Bolívar Impresores.

Puyana. A. (2013). El Sistema General de Riesgos Laborales en Colombia. Bogotá D.C: Universidad Externado de Colombia.

Sierra, J. (1999). Diccionario jurídico: Ajustado a la legislación colombiana. Medellín: Librería jurídica Sánchez. Ltda.

SafetYA ${ }^{\circledast}$. (2018). Matriz de requisitos legales del SG-SST: ¿Cómo elaborarla?. Recuperado de: https://safetya.co/la-matriz-de-requisitos-legales-del-sg-sst.

The W. Edwards Deming Institute. (2020). deming. Retrieved from PDSA Cycle: https://deming.org/explore/pdsa/

Lizarazo,C., Fajardo J, Berrio s., y Quintana L. (2010). Breve historia de la salud ocupacional en Colombia. Researchgate. Disponible en: https://www.researchgate. net/profile/Cesar Lizarazo/publication/228637429 Breve historia de la salud ocupacional en Colombia/links/0c960515c8b20f2642000000/Breve-historia-de-la-salud-ocupacional-en-Colombia.pdf.

Restrepo V., Román, \& Pérez R., Pascual, \& Escobar P., Martha L. (2009). Evolución del sistema general de riesgos profesionales, Colombia 1994 - 2004. Revista Facultad Nacional de Salud Pública, 27(2),226-238. [fecha de Consulta 13 de Septiembre de 2020]. ISSN: 0120-386X. Disponible en: https://www.redalyc.org/articulo. oa?id=120/12011791014

\section{Leyes y Jurisprudencia}

Congreso de Colombia. (16 julio de 1979). Por la cual se dictan Medidas Sanitarias. [Ley 9 de 1979].DO: 35308. Recuperado de: http://www.secretariasenado.gov. co/senado/basedoc/ley 0009 1979.html.

Congreso de Colombia.(23 de diciembre de 1993). Por la cual se crea el sistema de seguridad social integral y se dictan otras disposiciones.[ Ley 100 de 1993]. D0: 41.148. Recuperado de: http://www.secretariasenado.gov.co/senado/basedoc/ ley 0100 1993.html. 
Congreso de Colombia.(22 de junio de 1994). Por el cual se determina la organización y administración del Sistema General de Riesgos Profesionales. [ Decreto 1295 de 1994]. D0: 41.405. Recuperado de: http://www.secretariasenado.gov. co/senado/basedoc/decreto 1295 1994.html.

Congreso de Colombia.(18 de enero de 1995). Por la cual se dictan disposiciones para el fomento del deporte, la recreación, el aprovechamiento del tiempo libre y la Educación Física y se crea el Sistema Nacional del Deporte.[ Ley 181 de 1995]. D0:41.679. Recuperado de: http://www.secretariasenado.gov.co/senado/ basedoc/ley 0181 1995.html.

Congreso de Colombia. (17 diciembre de 2002). Por la cual se dictan normas sobre la organización, administración y prestaciones del Sistema General de Riesgos Profesionales.[Ley 776 de 2002].DO: 45.037. Recuperado de: http://www.secretariasenado.gov.co/senado/basedoc/ley 0776 2002.html.

Congreso de Colombia.(29 de enero de 2003). Por la cual se reforman algunas disposiciones del sistema general de pensiones previsto en la Ley 100 de 1993 y se adoptan disposiciones sobre los Regímenes Pensionales exceptuados y especiales.[ Ley 797 de 2003]. D0: 45.079. Recuperado de : http://www.secretariasenado.gov.co/senado/basedoc/ley 0797 2003.html.

Congreso de Colombia.(23 de enero de 2006). Por medio de la cual se adoptan medidas para prevenir, corregir y sancionar el acoso laboral y otros hostigamientos en el marco de las relaciones de trabajo.[ Ley 1010 de 2006].D0: 46.160. Recuperado de: http://www.secretariasenado.gov.co/senado/basedoc/ley 1010 2006.html.

Congreso de Colombia.(21 de julio de 2009). Disposiciones por medio de las cuales se previenen daños a la salud de los menores de edad, la población no fumadora y se estipulan políticas públicas para la prevención del consumo del tabaco y el abandono de la dependencia del tabaco del fumador y sus derivados en la población colombiana.[ Ley 1335 de 2009].DO: 47.417. Recuperado de: http:// www.secretariasenado.gov.co/senado/basedoc/ley 1335 2009.html.

Congreso de Colombia.(11 de julio de 2013). Por medio de la cual se expide la ley de Salud Mental y se dictan otras disposiciones.[ Ley 1616 de 2013].DO:. 48.680. Recuperado de: http://www.secretariasenado.gov.co/senado/basedoc/ ley 1616 2013.html.

Congreso de Colombia.(24 de abril de 2012). Por la cual se adopta la política nacional de gestión del riesgo de desastres y se establece el Sistema Nacional de Gestión del Riesgo de Desastres y se dictan otras disposiciones.[ Ley 1523 de 2012].D0: 48.411. Recuperado de: http://www.secretariasenado.gov.co/senado/basedoc/ ley $15232012 . \mathrm{html}$.

Congreso de Colombia.(11 de julio de 2012). Por la cual se modifica el Sistema de Riesgos Laborales y se dictan otras disposiciones en materia de Salud Ocupacional. [ Ley 1562 de 2012].DO: 48.488. Recuperado:http://www.secretariasenado.gov.co/senado/basedoc/ley_1562_2012.html. 
Congreso de Colombia.(15 de agosto de 2001). Por la cual se expide el Código de Minas y se dictan otras disposiciones.[ Código de Minas].DO: 44.545. Recuperado: http://www.secretariasenado.gov.co/senado/basedoc/ley 0685 2001.html.

Concejo de Bogotá. (29 junio de 2006). Por medio del cual se establece la obligatoriedad del uso de elementos de primeros auxilios en establecimientos de comercio y centros comerciales y se dictan otras disposiciones. [Acuerdo 230 de 206]. RD: 3568. Recuperado de: https://www.alcaldiabogota.gov.co/sisjur/normas/Norma1.jsp?i=20559.

Corte Constitucional. (26 de enero de 2011). Sentencia C-027/11. [M.P. Jorge Ignacio Pretelt]

Corte Constitucional. (26 de enero de 2000). Sentencia C-037 de 2000. [MP VLADIMIRO NARANJO MESA]

Corte Constitucional. (04 de febrero de 2003) Sentencia C-067/03.[MP Marco Gerardo Monroy Cabra]

Corte Constitucional. (26 de enero de 2000) Sentencia C-037/0.[MP Vladimiro Naranjo Mesa]

Corte Suprema de Justicia. Sala de Casación Laboral. Sentencia SL4570-2019. Número de radicado 78718.[MP Clara Cecilia Dueñas Quevedo].

Ministerio de Trabajo y Seguridad Social y Salud. (31 de marzo de 1986). Por la cual se reglamenta la organización, funcionamiento y forma de los Programas de Salud Ocupacional que deben desarrollar los patronos o empleadores en el país. [Decreto 1016 de 1986]. Recuperado de :https://www.alcaldiabogota.gov.co/sisjur/normas/Norma1.jsp?i=5412.

Presidente de la República. (14 de marzo de 1984). Por el cual se determinan las bases para la organización y administración de Salud Ocupacional en el país. [Decreto 614 de 1984]. Recuperado de:http://www.bogotajuridica.gov.co/sisjur/ normas/Norma1.jsp?i=1357.

Presidencia de Colombia. (01 de junio de 1994). Por el cual se sistematizan, coordinan y reglamentan algunas disposiciones en relación con el porte y consumo de estupefacientes y sustancias psicotrópicas. [Decreto 1108 de 1994]. D0: 41.375. Recuperado de: https://www.alcaldiabogota.gov.co/sisjur/normas/Norma1. jsp?i=6966.

Presidencia de Colombia. (30 de noviembre de 1994. Por el cual se expide la Tabla Única para las indemnizaciones por pérdida de la capacidad laboral entre el 5\% y 49.99\% y la prestación económica correspondiente. [Decreto 2644 de 1994]. D0: 41.375. Recuperado de : https://www.alcaldiabogota.gov.co/sisjur/normas/ Norma1.jsp?i=6966.

Presidencia de Colombia. (19 de febrero de 2014). Por el cual se reglamenta la gestión integral de los residuos generados en la atención en salud y otras actividades. [Decreto 351 de 2014]. DO:. 49069. Recuperado de : http://suinjuriscol.gov.co/ viewDocument.asp?id=1849406\#ver 1849434. 
Presidencia de Colombia. (08 de noviembre de 1995). Por medio del cual se promulga el Convenio 167 sobre Seguridad y Salud en la Construcción, adoptado por la Conferencia General de la Organización Internacional del Trabajo el 20 de junio de 1988. [Decreto 1972 de 1995]. D0:. 42080. Recuperado de: http://www.suinjuriscol.gov.co/viewDocument.asp?ruta=Decretos/1379314.

Ministerio de Trabajo y Seguridad Social. (22 mayo de 1979). Por la cual se dicta el Reglamento de Higiene y Seguridad para la Industria de la Construcción. [Resolución 2413 de 1979]. Recuperado de: https://www.icbf.gov.co/cargues/avance/ docs/resolucion mintrabajo rt241379.htm.

Ministerio de Trabajo y Seguridad Social. (5 agosto de 2014. Por el cual se expide la Tabla de Enfermedades Laborales. [Decreto 1477 de 2014]. DO: 49234. Recuperado de: https://www.alcaldiabogota.gov.co/sisjur/normas/Norma1.jsp?i=58849.

Ministerio de Trabajo y Seguridad Social. (31 julio de 2002). por el cual se modifica la Tabla de Clasificación de Actividades Económicas para el Sistema General de Riesgos Profesionales y se dictan otras disposiciones. [Decreto 1607 de 2002]. D0: 44892. Recuperado de: http://www.suin-juriscol.gov.co/viewDocument.as$\mathrm{p}$ ?id=1318005.

Departamento Administrativo de la Función. (10 enero de 2012). Por el cual se dictan normas para suprimir o reformar regulaciones, procedimientos y trámites innecesarios existentes en la Administración Pública.[Decreto <Ley>19 de 2012]. D0: 48.308. Recuperado de: http://www.secretariasenado.gov.co/senado/basedoc/ decreto 0019 2012.html.

Ministerio de Trabajo y Seguridad Social. (26 mayo de 2015). Por medio del cual se expide el Decreto Único Reglamentario del Sector Trabajo. [Decreto 1072 de 2015]. D0: 49523. Recuperado de: http://www.suin-juriscol.gov.co/viewDocument.asp?id=30019522.

Ministerio de Salud y Protección Social. (6 mayo de 2016). Por medio del cual se expide el Decreto Único Reglamentario del Sector Salud y Protección Social. [Decreto 780 de 2016]. D0:49.865. Recuperado de: https://www.icbf.gov.co/cargues/avance/docs/decreto 0780 2016.htm.

Ministerio de Salud y Protección Social. (20 mayo de 2020). Por medio de la cual se adopta el protocolo de bioseguridad para el manejo y control del riesgo de la enfermedad COVID 19 en el sector de Minas y Energía. [Resolución 797 de 2020]. D0: 51321. Recuperado de: https://www.minsalud.gov.co/Normatividad Nuevo/ Resolución\%20No.\%20797\%20de\%202020.pdf.

Ministerio de Salud y Protección Social. (22 febrero de 2018). Por la cual se reglamenta el uso de equipos generadores de radiación ionizante, su control de calidad, la prestación de servicios de protección radiológica y se dictan otras disposiciones. [Resolución 482 de 2018]. DO: 50.515. Recuperado de: https://www.icbf.gov.co/ cargues/avance/docs/resolucion minsaludps 0482 2018.htm. 
Ministerio de Salud y Protección Social. (10 junio de 2020). Por medio de la cual se adopta el protocolo de bioseguridad para el manejo y control del riesgo del coronavirus COVID- 19 en el sector de la Construcción y obras a ejecutar en los hagares e instituciones habitadas según Clasificación Internacional Industrial Uniforme - CIIU 4330. [Resolución 898 de 2020]. D0: 51341. Recuperado de: https://www.minsalud.gov.co/Normatividad Nuevo/Resolución\%20No.898\%20 de\%202020.pdf.

Ministerio de Salud y Protección Social. (24 abril de 2020. Por medio de la cual se adopyta el protocolo de bioseguridad para el manejo y control del riesgo de Coronavirus COVID-19 en el sector de la construcción de Edificaciones. [Resolución 682 de 2020]. D0: 51298. Recuperado de: https://www.minsalud.gov.co/ Normatividad_Nuevo/Resolucion\%20No.\%20682\%20\%20de\%202020.pdf.

Presidencia de la Republica. (20 diciembre de 2017). Por medio del cual se adoptan directrices generales para la elaboración del plan de gestión del riesgo de desastres de las entidades públicas y privadas en el marco del artículo 42 de la ley 1523 de 2012. [Decreto 2157 de 2017]. DO: 50453. Recuperado de: https://www. alcaldiabogota.gov.co/sisjur/normas/Norma1.jsp?i=73463.

Ministerio de Trabajo. (19 mayo de 2020). Por el cual se incorpora una enfermedad directa a la tabla de enfermedades laborales y se dictan otras disposiciones. [Decreto 676 de 2020]. Recuperado de: http://www.suin-juriscol.gov.co/archivo/ decretoscovid/DECRET0676DE2020.pdf.

Ministerio de Trabajo. (13 febrero de 2019). Por la cual se definen los Estándares Mínimos del Sistema de Gestión de la Seguridad y Salud en el Trabajo SG-SST. [Resolución 312 de 2019]. Recuperado de: https://www.mintrabajo.gov.co/documents/20147/59995826/Resolucion+0312-2019-+Estandares+minimos+del+Sistema+de+la+Seguridad+y+Salud.pdf.

Ministerio de la Protección Social. (11 julio de 2017). Por la cual se regula la práctica de evaluaciones médicas ocupacionales y el manejo y contenido de las historias clínicas ocupacionales. [Resolución 2346 de 2017]. Recuperado de: https://www. icbf.gov.co/cargues/avance/docs/resolucion minproteccion 2346 2007.htm.

Ministerio de la Protección Social. (24 mayo de 2007). Por la cual se reglamenta la investigación de incidentes y accidentes de trabajo. [Resolución 1401 de 2007]. Recuperado de: https://www.minsalud.gov.co/sites/rid/Lists/BibliotecaDigital/ RIDE/DE/DIJ/resolucion-1401-2007.pdf.

Ministerio de Trabajo y Seguridad Social. (22 mayo de 1979). Por la cual se establecen algunas disposiciones sobre vivienda, higiene y seguridad en los establecimientos de trabajo. [Resolución 2400 de 2019]. Recuperado de: http://www.bogotajuridica.gov.co/sisjur/normas/Norma1.jsp?i=53565.

Ministerio de Trabajo y Seguridad Social y Salud. (6 junio de 1986). Por la cual se reglamenta la organización y funcionamiento de los Comités de Medicina, Higiene y Seguridad Industrial en los lugares de trabajo.[Resolución 2013 de 1986]. Recuperado de: https://www.icbf.gov.co/cargues/avance/docs/resolucion minsalud r2013 86.htm. 
Ministerio de Trabajo. (30 abril de 2012). Por la cual se establece la conformación y funcionamiento del Comité de Convivencia Laboral en entidades públicas y empresas privadas y se dictan otras disposiciones. [Resolución 652 de 2012]. DO: 48.427. Recuperado de: https://www.icbf.gov.co/cargues/avance/docs/resolucion mtra 0652 2012.htm.

Ministerio de Salud y Protección Social. (24 abril de 2020).Por medio del cual se adopta el protocolo general de bioseguridad para mitigar, controlar y realizar el adecuado manejo de al pandemia del coronavirus COVID 19.[Protocolo 666 de 2020]. Recuperado de: https://coronaviruscolombia.gov.co/Covid19/docs/ decretos/minsalud/272 RESOLUCION 666 2020.pdf.

Ministerio de Salud y Protección Social. (14 julio de 2020). Por medio de la cual se adopta el protocolo de bioseguridad para el manejo y control del riesgo del coronavirus COVID-19 en la prestación de los servicios de salud, incluidas las actividades administrativas, de apoyo y alimentación. [Resolución 1155 de 2020]. D0: 51375. Recuperado de: https://www.minsalud.gov.co/Normatividad Nuevo/ Forms/DispForm.aspx?ID=6160.

Ministerio de Salud y Protección Social. (2 septiembre de 2020). Por medio d ela cual se adopta el protocolo de bioseguridad para el manejo y control del riesgo de coronavirus COVID- 19 en el sector Transporte. [Resolución 677 de 2020]. DO: 51300. Recuperado de: https://www.minsalud.gov.co/Normatividad Nuevo/ Resolución\%20No.677\%20de\%202020.pdf.

Ministerio de Salud y Protección Social. (11 junio de 2020). Por medio de la cual se adopta el protocolo de bioseguridad para el manejo y control del riesgo del coronavirus COVID- 19 en el sector portuario exclusivamente para transporte de carga. [Resolución 904 de 2020]. D0: 51342. Recuperado de: https://www. minsalud.gov.co/Normatividad Nuevo/Resolución\%20No.\%20904\%20de\%20 2020.pdf.

Congreso de la Republica. (26 junio de 2012). Por medio de la cual se implementa el certificado de aptitud psicofísica para el porte y tenencia de armas de fuego y se dictan otras disposiciones. [Ley 1539 de 2012]. D0: 48.473. Recuperado de: http://www.secretariasenado.gov.co/senado/basedoc/ley 1539 2012.html.

Ministerio de Defensa Nacional. (22 noviembre de 2012). Por el cual se reglamenta parcialmente la Ley 1539 de 2012 y se dictan otras disposiciones. [Decreto 2368 de 2012]. D0: 48.622. Recuperado de: https://www.icbf.gov.co/cargues/avance/ docs/decreto 2368 2012.htm.

Ministerio de Defensa Nacional. (17 abril de 2013). Por el cual se reglamenta parcialmente la Ley 1539 de 2012 y se dictan otras disposiciones. [Decreto 738 de 2013]. D0: 48764. Recuperado de: http://www.suin-juriscol.gov.co/viewDocument.asp?id=1156732. 
Ministerio de Defensa Nacional. (12 enero de 2017). Por el cual se reglamenta el Sistema Integrado de Seguridad para la expedición del certificado de aptitud psicofísica previsto en la Ley 1539 de 2012, se adicionan los Decretos 1070 de 2015 y 1079 de 2015, y se dictan otras disposiciones. [Decreto 026 de 2017]. DO: 50114. Recuperado de: https://www.alcaldiabogota.gov.co/sisjur/normas/ Norma1.jsp?i=67907.

Congreso de la Republica. (29 diciembre de 2013). Por la cual se promueve la formación de hábitos, comportamientos y conductas seguros en la vía y se dictan otras disposiciones. [Ley 1503 de 2011].D0: 48.298. Recuperado de: http://www. secretariasenado.gov.co/senado/basedoc/ley 1503 2011.html.

Ministerio de Transporte. (6 diciembre de 2013). Por el cual se reglamentan los artículos 3o, 40, 50, 6o, 7o, 9o, 10, 12, 13, 18 y 19 de la Ley 1503 de 2011 y se dictan otras disposiciones.[Decreto 2851 de 2013]. D0: 48.996. Recuperado de: https://www.icbf.gov.co/cargues/avance/docs/decreto 2851 2013.htm

Alcaldía Mayor de Bogotá D.C. (5 febrero de 2009). Por el cual se establecen condiciones para el tránsito de vehículos de carga en el área urbana del Distrito Capital y se dictan otras disposiciones. [Decreto 034 de 2009]. Recuperado de:. https://www.bogotajuridica.gov.co/sisjur/normas/Norma1.jsp?i=34947\&dt=S.

Ministerio de Transporte. (6 abril de 2017). Por el cual se adiciona la Parte 4 del Libro 2 del Decreto 1079 de 2015 y se reglamentan los artículos 84 de la Ley 1523 de 2012 y 12 y 63 de la Ley 1682 de 2013, en relación con la gestión del riesgo de desastres en el Sector Transporte y se dictan otras disposiciones. [Decreto 602 de 2017]. D0: 50.198. Recuperado de: https://www.alcaldiabogota.gov.co/sisjur/ normas/Norma1.jsp?i=68786\&dt=S.

Ministerio de Transporte. (6 junio de 2014). Por la cual se expide la Guía metodológica para la elaboración del Plan Estratégico de Seguridad Vial. [Resolución 1565 de 2014].Recuperado de: https://www.alcaldiabogota.gov.co/sisjur/normas/Norma1.jsp?i=75088\&dt=S.

Superintendencia de Puertos y Transporte. (16 noviembre de 2017). Revisión de los Planes Estratégicos de Seguridad Vial. [Circular Externa No. 00006816 Nov de 2017].Recuperado de: https://www.supertransporte.gov.co/documentos/2017/ Noviembre/Notificaciones 16 C/CIRCULAR 68 2017.pdf.

Ministerio de Salud, Ministerio de trabajo y Protección Social y Ministerio de Vivienda. (11 abril de 2020). ORIENTACIONES SOBRE MEDIDAS PREVENTIVAS Y DE MITIGACIÓN PARA REDUCIR LA EXPOSICIÓN Y CONTAGIO POR INFECCIÓN RESPIRATORIA AGUDA CAUSADA POR EL SARS-CoV-2 (COVID-19). [CIRCULAR CONJUNTA 001 del 11 de Abril de 2020].Recuperado de: https://www.minsalud.gov. co/RID/circular-conjunta-001-abril-2020.pdf.

Congreso de la Republica. (2 mayo de 2017). Por medio de la cual se regula el uso del Desfibrilador Externo Automático (DEA), en transportes de asistencia, lugares de alta afluencia de público, y se dictan otras disposiciones. [Ley 1831 de 2017]. Recuperado de: https://www.minsalud.gov.co/Normatividad Nuevo/Ley\%20 1831\%20de\%202017.pdf. 
Ministerio de la Protección Social. (22 abril de 2004). Unificar las instrucciones para la vigilancia, control y administración del Sistema General de Riesgos Profesionales. [Circular Unificada 2004]. Recuperado de: https://coronaviruscolombia. gov.co/Covid19/docs/decretos/minsalud/272 RESOLUCION 666 2020.pdf.

Ministerio de la Protección Social. (09 julio de 2010). ESPACIOS LIBRES DE HUMO Y DE SUSTANCIAS PSICOACTIVAS (SPA) EN LAS EMPRESAS. [Circular 0038]. Recuperado de: https://www.arlsura.com/files/circular0038 2010.pdf.

Ministerio de Minas y Energía. (5 de noviembre de 1993). Por el cual se expide el Reglamento de Higiene y Seguridad en las Labores Mineras a Cielo Abierto. [Decreto 2222 de 1993].DO: 41.104. Recuperado de: https://www.icbf.gov.co/cargues/avance/docs/decreto_2222 1993.htm.

Ministerio de Minas y Energía. (10 de enero de 1993). Por el cual se dictan unas disposiciones en materia de seguridad minera. [Decreto 0035 de 1994].DO: 41.170. Recuperado de: https://www.icbf.gov.co/cargues/avance/docs/decreto 0035 1994.htm.

Ministerio de Minas y Energía. (21 de septiembre de 2015). Por el cual se establece el Reglamento de Seguridad en las Labores Mineras Subterráneas. [Decreto 1886 de 2015].DO: 49642. Recuperado de: https://www.anm.gov.co/?q=content/decreto-1886-de-2015minminas.

Organización Internacional de Normalización. (12 de marzo de 2008). Sistemas de gestión de la seguridad y salud en el trabajo - Requisitos con orientación para su uso. Recuperado de: http://ergosourcing.com.co/wp-content/uploads/2018/05/ iso-45001-norma-Internacional.pdf.

Organización Internacional del Trabajo. (15 de marzo de 2002). Directrices relativas a los sistemas de gestión de la seguridad y la salud en el trabajo (ILO-OSH 2001). Recuperado de: https://www.ilo.org/wcmsp5/groups/public/---dgreports/--dcomm/---publ/documents/publication/wcms publ 9223116341 es.pdf.

Consejo Colombiano de Seguridad. (Septiembre de 2019). GUÍA DEL SISTEMA DE SEGURIDAD, SALUD EN EL TRABAJO Y AMBIENTE PARA CONTRATISTAS RUC ${ }^{\circledR}$. Recuperado de: https://portal.ccs.org.co/img/OAUPE009_Guia_Para_Contratistas RUC Rev17.pdf.

Presidencia de Colombia. (31 de mayo de 2015).Decreto Único Reglamentario del Sector Trabajo. [Decreto 1072 de 2015]. D0: 41.620. Recuperado de: http://www. suin-juriscol.gov.co/viewDocument.asp?ruta=Decretos/1475751.

Presidencia de Colombia. Por medio del cual se modifica el artículo 2.2.4.6.37. del Decreto 1072 de 2015, Decreto Único Reglamentario del Sector Trabajo, sobre la transición para la implementación del Sistema de Gestión de la Seguridad y Salud en el Trabajo (SG-SST). [ Decreto 52 de 2017]. 